\title{
FURTHER STUDIES ON TYPHOIDIN *
}

\author{
JOHN N. FORCE, M.D., AND IDA M. STEVENS, M.A. \\ BERKELEY, CALIF.
}

This paper records the results of further studies on typhoidin made since the publication of the original article of Gay and Force.

Since Gay and Force ${ }^{1}$ have reviewed the work on the application of preparations of the typhoid organism to the skin which had been published previous to their article, we shall confine ourselves to a review of observations on typhoidin which have appeared since that date.

The original typhoidin employed by Gay and Force consisted of a ten-day culture of a single strain of Bacillus typhosus on glycerin broth evaporated to one-tenth volume. On account of deterioration of the preparation in this form, Gay and Claypole ${ }^{2}$ precipitated the original typhoidin with twenty volumes of alcohol, filtered, washed with absolute alcohol and ether, and then dried on porcelain plates over sulphuric acid in a vacuum. With a freshly prepared suspension of this typhoidin powder in phenolated saline, equivalent in concentration to the original typhoidin, these authors were able to produce marked intradermal reactions in previously immunized rabbits, but not in controls. The reaction was characterized by the appearance within twenty-four hours of an indurated, reddened papule, which persisted at the site of inoculation for several days. Gundrum ${ }^{3}$ was unable to produce positive reactions in six typhoid cases by the intradermal injection of 0.1 c.c. doses of a commercial typhoid vaccine representing a suspension of 100 million organisms to 1 c.c. Positive results were secured in ten typhoid cases out of thirteen by a similar injection of Gay-Claypole vaccine, representing a suspension of 0.1 mg. ( 800 million) dried and ground sensitized typhoid organisms to 1 c.c. A red maculopapule appearing at the site between six and forty-eight hours after inoculation was considered positive if it equaled in size the original wheal produced by the intradermal injection.

* Submitted for publication Sept. 14, 1916.

* From the Laboratory of Hygiene and the Hearst Laboratory of Pathology and Bacteriology, University of California.

1. Gay, F. P., and Force, J. N.: A Skin Reaction Indicative of Immunity Against Typhoid Fever, The Archives Int. Med., 1914, 13, 471.

2..Gay, F. P., and Claypole, Edith J.: An Experimental Study of Prophylactic Immunization Against Typhoid Fever, The Archives Int. Med., 1914, 14, 671 .

3. Gundrum: Skin Test in Typhoid, California State Jour. Med., 1915, 13, 43. 
These results are open to the objection that Gay and Claypole ${ }^{2}$ have shown that marked reactions may be produced in normal persons by the intradermal injection of a suspension of sensitized vaccine representing from $0.5 \mathrm{mg}$. to $5 \mathrm{mg}$. to $1 \mathrm{c.c}$. In justice to Gundrum, however, it should be stated that he failed to produce reactions in eight controls, and eight of nine malaria patients. Pulay ${ }^{4}$ was unable to produce satisfactory results with a typhoidin made from a laboratory strain over a year old. With a typhoidin prepared from a recently isolated strain he secured negative reactions in twenty-eight normal subjects. Positive reactions were obtained in six typhoid patients, thirty-five convalescents, five persons with a history of typhoid long ago, and thirty-nine persons previously vaccinated. In reading the results Pulay lays particular stress on the persistence of the maculopapule, which may be distinct in normals at the end of twenty-four hours, but never after forty-eight hours. In the immunized person, however, the papule may be distinct even on the third day. The preparation used by Pulay was original typhoidin concentrated by evaporation at $40 \mathrm{C}$. in a vacuum.

Mehler, ${ }^{5}$ using original typhoidin, secured negative results in ten normal persons. Positive reactions were produced in eight of ten persons with a history of typhoid (one fifty years, one thirty years, one nineteen years, one fifteen years and again three and one-half years, and four three and one-half years previously) and negative reactions in two persons with a history of typhoid three and one-half years previous to the test. Of ten persons receiving two injections of typhoid vaccine three and one-half years previous to the test, only one gave a positive reaction, while thirteen of twenty persons receiving three injections three and one-half years previous to the test gave positive reactions.

Nichols ${ }^{6}$ by cutaneous application of a typhoidin powder reached the following conclusions:

1. The test was negative in 25 per cent. of cases with a history of typhoid, while typhoid fever is supposed to give 95 per cent. immunity.

2. The test was negative in 36 per cent. of those vaccinated under four years previous to the test, while experience has shown that vaccination protects in more than 64 per cent. of cases.

3. A preparation of $B$. paratyphosus $A$ gave 66 per cent, of positive reactions in cases giving 75 per cent. reactions to typhoidin,

4. Pulay: Diagnostiche Hautreaktion bei Typhusrekonvaleszenten, Typhuskranken und Schutzegeimpften mit Typhin nach Gay and Force, Wein. klin. Wchnschr., 1915, 28, 1189.

5. Mehler: Oration on Medicine-Prophylaxis of Typhoid Fever, Jour. Iowa State Med. Soc., 1916, 6, 99.

6. Nichols: Antityphoid Vaccination, Jour. Exper. Med., 1915, 22, 780. 
whereas there is no immunity to paratyphoid after typhoid immunization.

4. A positive typhoidin reaction is indicative of a history of typhoid fever or typhoid immunization, but a negative reaction is not necessarily indicative of the opposite condition.

Nichols interpreted his reactions according to the original criteria of Gay and Force; a difference in diameter between typhoidin and control spots of at least $2.5 \mathrm{~mm}$. twenty-four hours after the application of the test. Had he waited for the toxic action to subside (fortyeight hours) his results with paratyphoidin might have been different. His results with typhoidin are practically identical with ours, since we obtained negative reactions in 23 per cent. of patients with history of typhoid and 36 per cent. of persons vaccinated under four years previous to the test. We are not prepared, however, to agree with his statement of the percentage of recovered typhoid patients who are protected. Sawyer ${ }^{7}$ found a history of previous typhoid in 15 per cent. of cases in an epidemic occurring in Hanford, Calif., while Kelly ${ }^{8}$ secured a similar history from 8.2 per cent. of cases at Taft, Calif.

Austrian and Bloomfield ${ }^{9}$ employed suspensions of dried typhoidin powders derived from both a single and several strains of $B$. typhosus. These suspensions were injected intradermally in doses ranging from $0.00001 \mathrm{gm}$. to $0.02 \mathrm{gm}$. of the dried powder. The original criteria of Gay and Force were employed in interpreting the reactions, which were positive in all of sixty-six cases comprising normal persons, those previously vaccinated, and persons with a history of typhoid. In several cases they report local and general reactions comparable to those following typhoid vaccination. These results of Austrian and Bloomfield were in no way remarkable when the amount of typhoidin used is considered, together with the failure to wait for the subsidence of the irritant effect of the protein. Gay and Claypole have shown that the evaporation of 10 c.c. of typhoidin broth will yield ' $0.78 \mathrm{gm}$. of powder, while the evaporation of an equal amount of control broth will yield $0.5 \mathrm{gm}$. of powder. Not allowing for the increase in typhoid organisms at the expense of the broth, we may assume that any quantity of typhoidin powder contains one-third its weight of typhoid bacilli. The ordinary immunizing dose of typhoid vaccine used by us contains $0.0001 \mathrm{gm}$. of typhoid bacilli, equivalent to $0.0003 \mathrm{gm}$. of typhoidin. Doses of typhoidin then ranging from $0.00001 \mathrm{gm}$. to $0.02 \mathrm{gm}$. represent vaccinations with from one-thirtieth

7. Sawyer: Ninety-Three Persons Infected by a Typhoid Carrier at a Public Dinner, Jour. Am. Med. Assn., 1914, 63, 1537.

8. Kelly: Personal communication to the authors.

9. Austrian and Bloomfield: The Typhoidin Reaction, The Archives Int. Med., 1916, 17, 663. 
to sixty-six times the ordinary dose of typhoid vaccine. A normal person might be expected to show local and general reactions to the larger dose, while a previously sensitized person might give a similar reaction to the smaller dose. Positive reactions in the previously vaccinated person could easily be confused with local reactions produced by intradermal vaccination of normal persons.

Kilgore $^{10}$ has suggested the use of a quotient for recording the results of cutaneous tests obtained by dividing the diameter of the allergic reaction by the diameter of its control. He regards a quotient over 1.5 as positive, basing his opinion on a number of experiments in the application of typhoidin to the scarified skin. $\mathrm{He}$ has pointed out the difficulty of securing uniform scarifications and the impossibility of applying to them constant amounts of the powder. Another element of unreliability in the reaction is a strong irritant effect of the powder itself, which tends to overshadow a weaker specific action. In another communication Kilgore ${ }^{11}$ has shown that the higher the typhoidin quotient the greater the chance of reaction to vaccination, and that those who react least to vaccination profit most by its administration, if increase in the typhoidin quotient after vaccination be considered evidence of increased immunity. Kilgore also gives experiences with the intradermal method of administering the typhoidin test. The dose used was approximately 0.05 c.c. of a 1 to 100 suspension of dry typhoidin powder, controlled by an equivalent dose of broth powder. Observations were made at the end of twenty-four hours and results recorded in terms of the typhoidin quotient. Kilgore states that there was practically no difference in the average quotients between a group of fifty-three supposedly immune persons and a group of thirty-eight with a negative typhoid history. Some persons in this series complained of malaise and chilliness, together with an arm as sore as if a typhoid vaccination had been taken. As in the case of Austrian and Bloomfield, the results of Kilgore are not surprising when we consider the doses of typhoidin used which he himself admits were probably too large. The ordinary dose of typhoid vaccine being $0.0001 \mathrm{gm}$. (equivalent to $0.0003 \mathrm{gm}$. of typhoidin), it is evident why normal persons should be confused with those who are immune and why both groups should complain of local and general reactions on receiving an intradermal dose of unsensitized killed typhoid organisms two-thirds greater than the quantity used in typhoid vaccination. The excessive dose, together with a twenty-four-hour observation, served to effectually mask any variations in sensitiveness which might otherwise have been apparent.

10. Kilgore: The Typhoidin Quotient, The Archives Int. Med., 1916, 17, 25.

11. Kilgore: A Comparison of Two Methods of Vaccinating Against Typhoid Fever, The Archives Int. Med., 1917, 19, 276. 
Kolmer and Berge ${ }^{12}$ have made a careful comparison of the typhoidin reaction with the agglutinins, bactericidins, and complement fixing antibodies present in the serum of typhoid immune persons. The typhoidin was injected intradermally in doses ranging from $0.0005 \mathrm{mg}$. to $0.001 \mathrm{mg}$, and the resulting reaction observed in twenty-four hours. A reaction was regarded as positive "when the typhoidin site alone showed a reaction or when this site had at least twice the area of erythema and" a greater edema than the control," as doubtful when the typhoidin site was one-third greater than the control, and as negative when there was "nothing more than trauma or an area of about equal degree in regard to erythema and edema." From observations on forty-two cases these authors conclude "that agglutinins are present in the blood serum of the majority of persons reacting positively in the skin test, but there is no definite relation. between the two as either may be in evidence in the absence of the other." They further mention an irritant action of the typhoidin and suggest the possibility of developing a typhoidin free from toxic substances. They found positive reactions in two of ten normal persons, six of ten persons with a history of typhoid, and twelve of twenty-two previously vaccinated. It is possible that these results might have been different had the reactions been observed at the end of fortyeight hours after the irritant effect of the protein had subsided.

\section{THE PREPARATION OF TYPHOIDIN}

Reference has already been made to a typhoidin powder which Gay and Claypole prepared by precipitating the original typhoidin with alcohol, washing with absolute alcohol and ether, and then drying on porcelain plates over sulphuric acid in a vacuum. It was anticipated that this dried typhoidin would retain its potency for a much longer period than the original concentrated glycerin broth preparation. In an attempt to avoid the necessity of weighing a small quantity of this powder whenever a fresh suspension was needed, Dr. Claypole prepared for one of us (Force) a number of small amber vials, each containing such a quantity of the powder that the addition of 1 c.c. of phenolated saline would furnish material for a number of tests. As the powder was believed to be stable, no especial precautions were observed in storing the vials, and we were therefore surprised to discover, on examining them some days later, that the powder had become a moist, treacle-like mass. Thereafter no attempt was made to prepare a saline suspension, but the powder was stored in a large vial in a desiccator, and applied directly to the scarified arm by means of the

12. Kolmer and Berge: The Relation of the Typhoidin Skin Reaction to Immunity in Typhoid, Jour. Immunol, 1916, 1, 409. 
chisel used in making the abrasion. The obvious tendency of the powder to absorb moisture, however, raised the question as to the possible hydrolyzing effect of the residual moisture during the rather slow process of drying over sulphuric acid. Studies were therefore made by one of us (Stevens) with a view to developing a method for the rapid dehydrating of the typhoidin powder to a constant weight, experience with other proteins having shown that a rapidly dehydrated preparation is extremely stable.

The method of preparation finally adopted was a modification of the technic of Gay and Claypole. Ten flasks, each containing 25 c.c. of meat infusion broth ( 1 per cent. peptone), were inoculated with ten different strains of $B$. typhosus, and incubated for ten days. The ten cultures were then poured into a large glazed porcelain dish and the mixture was evaporate $\dot{d}$ for sixteen hours over an acetone bath to one-tenth the original volume. This concentrated polyvalent culture was then transferred to a 500 c.c. stoppered cylinder, thirty volumes of 95 per cent. alcohol were added, the mixture thoroughly shaken and allowed to stand for twenty-four hours. At the end of this period the supernatant fluid was drawn off by means of a pipet attached to a filter pump, the precipitate washed in 95 per cent. alcohol, and allowed to stand until entirely settled. The alcohol was again drawn off and the precipitate washed twice with absolute alcohol, and the precipitate allowed completely to settle in each instance before removing the supernatant fluid. After the removal of the alcohol the precipitate was shaken up with absolute ether, allowed to settle, again shaken, the suspension poured onto a hard filter paper (C. S. \& S. 575 ), and the precipitate again washed with absolute ether, being careful to keep it covered with a watch glass while draining. The covered funnel containing the precipitate was immediately placed in an oven containing an open dish of sulphuric acid, and kept at a temperature of 40 degrees $C$. for thirty minutes. At the end of this time the watch glass was removed from the filter and the open filter left in the oven for eighteen hours. The filter paper was then removed from the funnel, opened out, and left in the oven until the precipitate crumbled readily. It was then transferred to an agate mortar, ground by hand, placed in a dark-colored, glass-stoppered vial, weighed, and exposed in a desiccator over sulphuric acid. When the powder has dried to constant weight the stopper may be inserted and sealed with paraffin.

The following comments on this method of preparation may perhaps be in order: (1) The different strains of $B$. typhosus used in making the polyvalent typhoidin were selected to represent the various 
antigenic properties described by Hooker. ${ }^{13}$ (2) The growth in each of the ten flasks was determined to be a pure culture before the strains were mixed. (3) As soon as the suspension of typhoidin in absolute ether is poured onto the filter it should be covered with the watch glass and kept covered, except when more ether is poured on for washing. A few seconds' exposure to the air at this stage will convert the precipitate into a gumlike mass, whereas the particles of typhoidin adhering to the mortar after the grinding show no tendency to deliquescence even after forty-eight hours' exposure. (4) In the absence of a vacuum chamber with thermostatic control, the ordinary gas oven may be used with hot bricks as radiators. The gas flame should be shut off before placing the filter in the oven. (5) Given the ten days' culture, three days should be sufficient for all of the steps, beginning with the concentration of the culture and ending with the exposure of the dry powder in the desiccator. The powder should be dried to constant weight in four days at the most. A period of eight weeks has been found necessary in some instances to prepare dry typhoidin according to the method of Gay and Claypole.

\section{THE TYPHOIDIN TEST AND ITS INTERPRETATION}

We have long recognized that the application of typhoidin to the scarified skin is open to the objections so well described by Kilgore. In entering on this series of studies, therefore, we determined to employ the more accurate method of intradermal injection.

Suspensions of typhoidin and its corresponding bouillon control were made in phenolated saline $(0.5$ per cent. phenol), so that 0.1 c.c. would contain $1 \mathrm{mg}$., $0.1 \mathrm{mg}$., or $0.01 \mathrm{mg}$. of the dried powder in each instance. Three rabbits which had been immunized against $B$. typhosus one year previously and reimmunized six weeks before the test were shaved on the back. On the following day they were inoculated intradermally with 0.1 c.c. of each suspension. Three normal rabbits served as controls. The results of this experiment are shown in Table 1 . It will be seen that the dose of $1 \mathrm{mg}$. of typhoidin is unduiy toxic, while the dose of $0.01 \mathrm{mg}$. did not produce a reaction in the immune animal distinguishable from the reaction in the normal. The medium and low doses were then given to L. R. T., a student, who had been vaccinated within the year. Reference to Table 1 will show that a dilution too high to give definite results in immune rabbits produced a distinct reaction in a previously vaccinated person.

13. Hooker: A Study of the Antigenic Properties of Different Strains of B. typhosus: Preliminary Communication, Proc. Soc. Exper. Biol. and Med., $1916,13,139$. 
Von Pirquet, ${ }^{14}$ Force and Beckwith, ${ }^{13}$ and Kolmer and Moshage ${ }^{16}$ have shown that irritation due to trauma is reduced to a minimum by intradermal inoculation of 0.05 c.c. of fluid. We therefore finally adopted a dose of $0.005 \mathrm{mg}$. of typhoidin suspended in 0.05 c.c. of phenolated saline, representing a dilution of 1 to 10,000 .

In interpreting the results of the typhoidin test, we have established the following criteria:

1. A positive reaction is indicated by the presence, forty-eight hours after the application of the test, of a maculopapule, with definite erythema measuring at least $5 \mathrm{~mm}$. in one diameter.

TABle 1.-Tests to Determine the Dosage of Typhoidin

\begin{tabular}{|c|c|c|c|c|c|c|}
\hline \multirow{2}{*}{ Subject } & \multirow{2}{*}{$\begin{array}{l}\text { Dose, } \\
\text { Mg. }\end{array}$} & \multicolumn{2}{|c|}{ Reaction First Day } & \multicolumn{2}{|c|}{ Reaction Secend Day } & \multirow{2}{*}{ Result } \\
\hline & & Typhoidin & Control & Typhoidin & |Control & \\
\hline $\begin{array}{l}\text { Rabbit } \\
\text { 1. Immune..... }\end{array}$ & 1 & $((28.3)$ & 7.6 & $(19.5)$ & 10.9 & Positive \\
\hline 2. Normal........... & 1 & 20.5 & 7.1 & 22.9 & 0 & Negative \\
\hline 3. Immune...... & 0.1 & $((17.5)$ & 5 & (9.9) & $\mathbf{0}$ & Positive \\
\hline 4. Normal........... & 0.1 & 16.8) & 0 & 12.8 & 0 & Negative \\
\hline 5. Immune........... & 0.01 & (16 & 7 & 5.6 & 2.8 & Negative \\
\hline 6. Normal........... & 0.01 & 16 & 11.8 & 6.5 & 0 & Negative \\
\hline \multirow[t]{2}{*}{$\begin{array}{l}\text { Human } \\
\text { L. R. T., vac. } 1915 \ldots . .\end{array}$} & 0.1 & $((65.3)((11.3)$ & 21 & $((99.8$ ((14) & 0 & Positive \\
\hline & 0.01 & (29.9) & 25 & $((76.1)((9.4)$ & 0 & Positive \\
\hline
\end{tabular}

2. A doubtful reaction is indicated by the absence of either induration or erythema at the end of forty-eight hours.

3. A negative reaction is indicated by the absence of both induration and erythema at the end of forty-eight hours.

Von Pirquet has shown that intradermal inoculations of vaccine lymph produce, in previously vaccinated persons, marked papules which increase in size to the forty-eighth hour and persist even to the seventy-second hour. A good reaction might be produced by this method when an equal amount applied to the scarified skin failed to

14. Von Pirquet: Ueber die verschiedenen Formen des allergeschen Reaction bei der Devaccination, Ztschr. f. Immunitätsforsch. u. exper. Therap., Orig., $1911, \mathbf{1 0}, 1$.

15. Force and Beckwith: A Laboratory Method for the Diagnosis of Smallpox, Jour. Am. Med. Assn., 1915, 65, 588.

16. Kolmer and Moshage: A Note on the Occurrence of Pseudoreactions on the Skin, with Special Reference to the Schick Toxin Test, Jour. Am. Med. Assn., 1915, 65, 144. 
produce results. Haring and Belli ${ }^{17}$ in observing the intradermal tuberculin reaction consider positive any induration at the point of inoculation larger than the head of a parlor match, increasing in size to the forty-eighth hour and persisting to the seventy-second hour. Gay and Claypole ${ }^{2}$ describe the typhoidin reaction on immune rabbits as a red areola with a nodule measuring from 2 to $5 \mathrm{~mm}$. which persists several days after the disappearance of the areola. Force and Beckwith ${ }^{15}$ have shown that smallpox vesicle contents inoculated intradermally into previously vaccinated rabbits will produce a red areola and infiltration appearing within twenty-four hours, but which may not reach its maximum until forty-eight hours. Kolmer and Moshage ${ }^{16}$ advise the interpretation of diphtheria toxin intradermal reactions on a forty-eight rather than a twenty-four hour basis, though this reaction is not allergic in the sense of the so-called pseudoreaction to diphtheria protein. Levinson ${ }^{18}$ would regard no diphtheria toxin test positive unless there was induration measuring at least $5 \mathrm{~mm}$. by $2 \mathrm{~mm}$. and persisting five days with change of color. Weil, ${ }^{18}$ in his intradermal tests to detect the presence of pneumonia antibodies, regards the reaction positive when there is an area of erythema and a papule persisting forty-eight hours or more. Combe, ${ }^{20}$ in his intradermal tuberculin tests in children, measures the papule present forty-eight hours after the injection of $0.1 \mathrm{mg}$. of tuberculin. Zingher ${ }^{21}$ describes the pseudoreactions obtained by the intradermal injection of diphtheria toxin as anaphylactic responses of the tissue cells to the protein substances of the autolyzed diphtheria bacilli in the toxic broth. The reaction appears early, within from six to eighteen hours, reaches its height in from thirty-six to forty-eight hours and disappears on the third or fourth day, leaving no pigmentation. It is characterized by a small central area of dusky red infiltration, with a secondary areola which shades off into the surrounding skin.

In all of these descriptions of skin tests there seems to be a disposition to recognize the persistence of a well-marked papule to the forty-eighth hour and erythema as more satisfactory criteria for positive reactions than any comparison of allergin with control. In fact in our later studies we have discontinued the use of the control

17. Haring and Bell: The Intradermal Test for Tuberculosis in Cattle and Hogs, Univ. Calif. Pub. Ag. Bull., No. 243, 1914.

18. Levinson: The Value and Limitations of the Schick Diphtheria Reaction, Illinois Med. Jour., 1915, 28, 405.

19. Weil: Note on a Skin Reaction in Pneumonia, Jour. Exper. Med., 1916, 23, 11 .

20. Combe: Diagnosis of Tuberculosis in Infants, Le Nourrisson, January, $1916,4,73$.

21. Zingher: Methods of Using Diphtheria Toxin in the Schick Test and of Controlling the Reaction, Am. Jour. Dis. Child., 1916, 11, 269. 
entirely. Typhoidin represents something more complicated than typhoid bacilli plus peptone broth. At the end of ten days of growth and digestion the organisms have seriously affected the peptone and beef proteins. It follows, therefore, that a powder produced by the evaporation of peptone broth cannot truly serve as a control to typhoidin. Since many persons give marked reactions to peptone broth, it would seem that any attempt to interpret the reaction in terms of the difference between the typhoidin spot and a broth control will lead to much misinterpretation of results.

Our determination to abandon the use of a broth control is in line with the procedure of Zingher, ${ }^{22}$ who, in the routine administration of the diphtheria toxin test, has substituted for the control broth a heated toxin, which is administered intradermally to those persons giving a doubtful reaction to the diphtheria toxin. Heating destroys the irritant action of the toxin and any reaction to this product would represent the uncomplicated allergic action of autolyzed diphtheria organisms, that is, the true pseudoreaction. The heated toxin then becomes, for the purpose of this reaction, an actual control to the unheated toxin. Zingher also has observed that persons giving the pseudoreaction, that is, presumably sensitized to diphtheria protein, were much more susceptible to the local action of antitoxin or immunizing injections of toxin-antitoxin. Weaver and Rappaport ${ }^{23}$ have noted that persons giving an intradermal pseudoreaction to diphtheria toxin are apt to give a similar reaction to a control of toxinantitoxin. These authors charge this result to the effect of horse serum, but it is also readily explained on the basis of allergic effects of autolyzed diphtheria organisms. Since Bessau and Schwenke ${ }^{24}$ have been unable to remove the allergic effect of autolyzed diphtheria organisms even by boiling diphtheria toxin, it follows that the question of a true control to typhoidin or other cutaneous allergins is still an open one.

\section{SPECIFICITY OF THE TYPHOIDIN REACTION}

We have suggested criteria for the interpretation of the typhoidin reaction independent of so-called controls. There remains still the question of specificity. In other words, is the typhoidin reaction due to a toxic effect of the inoculated protein on the tissues, or, even granting such an effect, is there in addition a specific reaction in persons sensitized to typhoid protein? If there is such a reaction how may it be unmasked from the stronger toxic influence?

22. Zingher: The Pseudoreaction in the Schick Test and Its Control, Jour. Am. Med. Assn., 1916, 66, 1617.

23. Weaver and Rappaport: Further Observations on the Schick Test for Diphtheria Immunity, Jour. Am. Med. Assn., 1916, 66, 1448.

24. Bessau and Schwenke: Ueber de lokale Diphtherie-Bouillon-Reaktion beim Menschen, Monatsch. f. Kinderh., 1916, 13, 397. 
Stokes $^{25}$ holds that many skin reactions are not specific in the sense that they are the results of antigen-antibody activity, but rather the results of the activity of an anaphylatoxin which will produce focal inflammation as the result of the action of the subject's enzymes on his own tissues. This anaphylatoxin is a product of the action of a protease released through parenteral introduction of antiferment adsorbents. On the other hand, Bronfenbrenner ${ }^{26}$ claims that more than mechanical action of antiferment adsorbents is involved in these reactions, since there is an element of specificity, not in the ferment, but in the mechanism of its activation. The combination of a specific serum with its corresponding antigen is followed by a change in the

TABLE 2.-DETAILS OF-

\begin{tabular}{|c|c|c|c|c|c|c|}
\hline \multirow{2}{*}{ Initials } & \multirow{2}{*}{ Class } & \multirow{2}{*}{$\begin{array}{l}\text { Date of } \\
\text { Test }\end{array}$} & \multicolumn{4}{|c|}{ Preparation } \\
\hline & & & MAc & MAl & PAc & PAI \\
\hline M. C...... & Normal. ................ & $2 / 23 / 16$ & $\#$ & $\ldots$ & $\ldots$ & $\ldots$ \\
\hline H. D. ........... & Normal...................... & $2 / 23 / 16$ & $\#$ & $\cdots$ & $\cdots$ & $\cdots$ \\
\hline M. S......... & Normal........................ & $4 / 3 / 16$ & $\cdots$ & $\#$ & $\cdots$ & $\cdots$ \\
\hline H. I. S.... & $\begin{array}{l}\text { History of Typhoid- } \\
1906 \ldots \ldots \ldots \ldots \ldots \ldots \ldots\end{array}$ & $3 / 22 / 16$ & $\cdots$ & $\cdots$ & $\cdots$ & $\cdots$ \\
\hline F. B.......... & 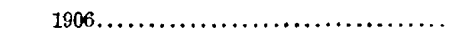 & $3 / 15 / 16$ & $\#$ & $\cdots$ & $\cdots$ & $\cdots$ \\
\hline R. L. S. ....... & $\begin{array}{l}\text { Vaccinated } 3 / 31 / 14,3 \text { doses; } 3 / 3 / 15,2 \\
\text { doses; typhoid } 5 / 25 / 15 \ldots \ldots \ldots \ldots \ldots \ldots\end{array}$ & $4 / 26 / 16$ & $\cdots$ & $\cdots$ & $\cdots$ & $\#$ \\
\hline D. G...... & 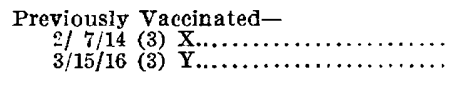 & $\begin{array}{l}3 / 1 / 16 \\
4 / 12 / 16\end{array}$ & $\#$ & $\ldots$ & $\dddot{\sharp}$ & $\ldots$ \\
\hline J. M. ......... & 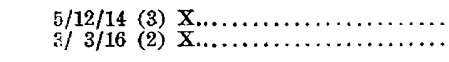 & $\begin{array}{l}2 / 25 / 16 \\
5 / 1 / 16\end{array}$ & $\#$ & $\cdots$ & $\cdots$ & $\dddot{\#}$ \\
\hline C. G. P..... & $\begin{array}{l}9 / 24 / 13(2) \times \ldots \ldots \ldots \ldots \ldots \ldots \ldots \ldots \ldots \\
4 / 3 / 16(3)\end{array}$ & $\begin{array}{l}3 / 27 / 16 \\
4 / 24 / 16\end{array}$ & $\#$ & $\cdots$ & $\cdots$ & $\dddot{\pi}$ \\
\hline
\end{tabular}

\# From February to May, 1916, inelusive.

degree of dispersion of serum colloids, which is in turn followed by the activation of the nonspecific ferment.

While we must admit that parenteral administration of foreign proteins gives rise to certain nonspecific responses, we hope to show in the case of typhoidin that these general reactions tend to subside by the forty-eighth hour; and further, that these reactions are proportional to the concentration of the suspension of typhoidin powder, so that the specific reaction appears to be unmasked by using small doses of the antigen.

25. Stokes: Studies on Intradermal Sensitizations, II. An Intradermal Reaction to Agar and an Interpretation of Intradermal Reactions, Jour. Infect. Dis., 1916, 18, 415.

26. Bronfenbrenner: Specific Parenteral Digestion and Its Relation to Phenomena of Immunity and Anaphylaxis, Jour. Lab. and Clin. Med., 1916, 1, 573. 
EXPLANATION OF THE TABLES

The accompanying tables, 2,3 and 4 , show the results of typhoidin tests on a group of faculty and students of the University of California.

A uniform dose of 0.05 c.c. of a suspension in phenolated $(0.5$ per cent. phenol) saline of $0.005 \mathrm{mg}$. of typhoidin was injected intradermally in each instance. Any injection failing to produce a white wheal with depressions marking the hair follicles was discounted in the estimation of results, but there was no attempt to produce wheals of constant diameter.

-Nine Typhoidin Tests

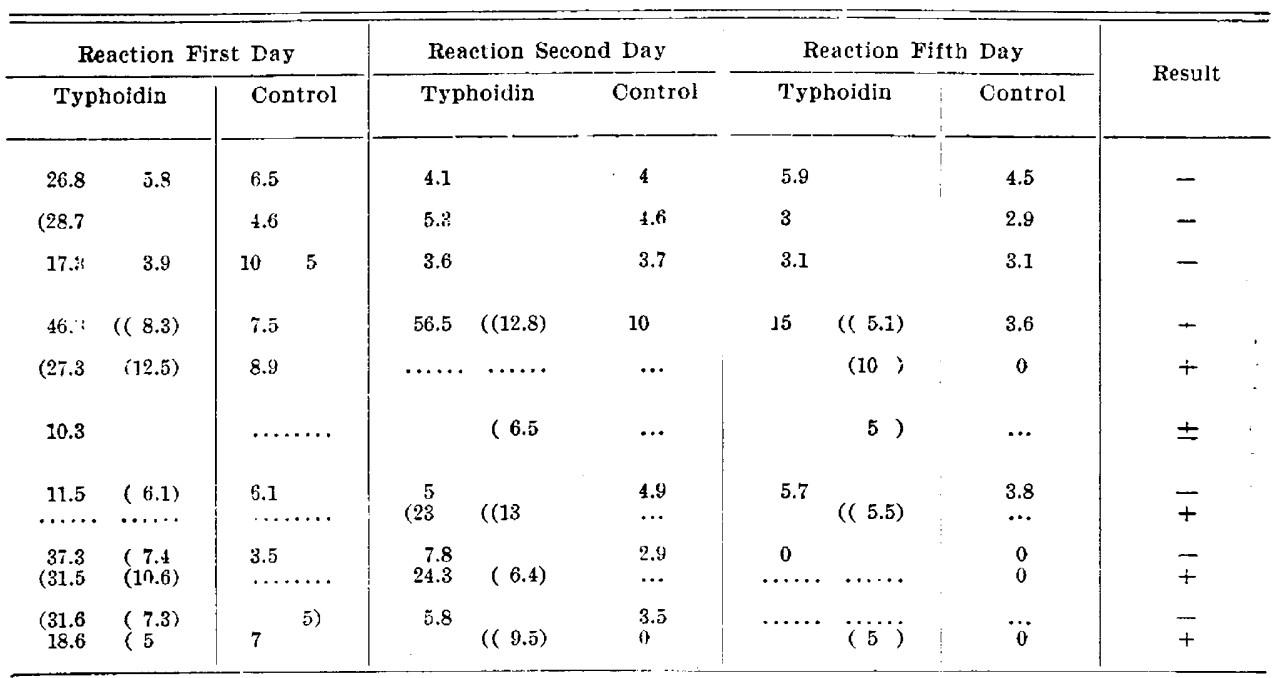

Table 2 gives the details of nine typhoidin tests and is presented in order to show the methods employed in recording the results obtained.

The preparations of typhoidin employed were a monovalent strain precipitated with acetone (MAc), a monovalent strain precipitated with alcohol (MAl), a polyvalent strain precipitated with acetone (PAc), and a polyvalent strain precipitated with alcohol (PAl), which was rapidly dehydrated.

In case the person had been previously vaccinated, the date of the last dose of vaccine is given, together with a figure, in parenthesis, indicating the number of doses of vaccine and a letter indicating the type of vaccine used. The types of vaccine which had been employed in the vaccination of this series were U. S. Army $(A)$, commercial $(C)$, Gay-Claypole $(X)$, and a vaccine prepared by the same technic as the latter but unsensitized $(Y)$. 
TABLE 3.-SumMary OF TyphoIdin Tests

\begin{tabular}{|c|c|c|c|c|}
\hline Clüss & Positive & Doubtful & Negative & Negative, \% \\
\hline Normals.............. & $1^{*}$ & .. & 17 & 94 \\
\hline $\begin{array}{l}\text { History of Typhoid: } \\
\text { 1899-1904............. }\end{array}$ & 5 & .. & $5 t$ & 50 \\
\hline 1905-1910............ & 9 & .. & 1 & 10 \\
\hline 1911-1916............ & $5 \vdots$ & 18 & .. & 0 \\
\hline 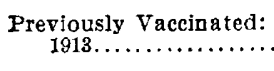 & 25 & 1 & 26 & 50 \\
\hline $1914 \ldots \ldots \ldots \ldots \ldots$ & 14 & 8 & 13 & 45 \\
\hline $1915 \ldots \ldots \ldots \ldots \ldots \ldots$ & 7 & 1 & 8 & 27 \\
\hline $1916 \sharp \ldots \ldots \ldots \ldots \ldots$ & $3 \pi$ & 7 & 12 & 21 \\
\hline
\end{tabular}

* For a history of the case of A. G. see matter under the head "Comment" In the text. Four of these gave questionable typhoid histories.

One of these gave a questionable typhoid history in 1915, but had been vaccinated in 1912 For a history of the case of R. L. S. see the case report under the head "Comment" in the text.

TABLE 4.-Reaction to Vaccination (or Revaccination) of Persons Previously Receiving Typhotdin Tests

\begin{tabular}{|c|c|c|c|c|c|c|c|c|c|c|c|c|c|c|c|c|}
\hline \multirow{3}{*}{ Class } & \multirow{3}{*}{$\begin{array}{l}\text { Result of } \\
\text { 'Test }\end{array}$} & \multirow{2}{*}{\multicolumn{3}{|c|}{$\begin{array}{l}\text { Persons Report- } \\
\text { ing after Each } \\
\text { Inoculation }\end{array}$}} & \multicolumn{6}{|c|}{ Local Reaction } & \multicolumn{6}{|c|}{ General Reaction } \\
\hline & & & & & \multicolumn{3}{|c|}{ Slight } & \multicolumn{3}{|c|}{ Severe } & \multicolumn{3}{|c|}{ Slight } & \multicolumn{3}{|c|}{ Severe } \\
\hline & & 1st & $2 d$ & $3 d$ & 1st & $2 d$ & $8 \mathrm{~d}$ & 1st & $2 \mathrm{~d}$ & $3 d$ & 1st & $2 \mathrm{~d}$ & $3 d$ & 1st & $2 \mathrm{~d}$ & $3 d$ \\
\hline \multirow[t]{2}{*}{ Normal........ } & Untested & 236 & 228 & 105 & 88 & 74 & 30 & 40 & 43 & 9 & 87 & 90 & 19 & 9 & 10 & 2 \\
\hline & Positive & 1 & .... & $\ldots$ & .. & .. & .. & 1 & .. & .. & .. & .. & .. & 1 & & \\
\hline \multirow{3}{*}{$\begin{array}{l}\text { Previously } \\
\text { vaccinated... }\end{array}$} & Negative & 8 & 8 & 3 & 3 & 3 & .. & 1 & 1 & 1 & 2 & & & & & \\
\hline & Positive & $\mathbf{3}$ & 1 & $\ldots$ & 1 & .. & .. & 2 & .. & .. & I & .. & .. & 2 & 1 & \\
\hline & Doubtful & 8 & 3 & 1 & 1 & .. & .. & 3 & 1 & 1 & 1 & .. & .. & 2 & 1 & \\
\hline \multirow{2}{*}{$\begin{array}{l}\text { History of } \\
\text { typhoid... }\end{array}$} & Negative & 48 & 84 & 21 & 15 & 6 & 3 & 9 & 5 & .. & 15 & 16 & 5 & 1 & 1 & \\
\hline & Negative & 5 & 2 & 1 & .. & .. & .. & 1 & .. & 1 & .. & . & 1 & 1 & 1 & \\
\hline
\end{tabular}

The measurements of the reactions were made with calipers in the longest diameter and recorded in millimeters. The numbers at the left of each column of measurements refer to the areolae, the numbers at the right to the papules. A well-marked areola is designated by the sign ( placed in front of the measurement. A well-marked papule is indicated by the sign ) placed after the measurement. If the erythema of the papule is well marked, the sign (is placed in front of the measurement. A double sign indicated great intensity of the reaction. For example: The record 25.4 ( (10.6) would indicate an areola of $25.4 \mathrm{~mm}$. not very well marked, with a central papule of $10.6 \mathrm{~mm}$. well marked and very red. Positive reactions are indicated by the sign + , doubtful by the sign \pm , and negative by the sign - . 
We are, of course, aware of the unreliability of personal statements regarding the presence or absence of a history of typhoid fever. The experience of Sawyer ${ }^{7}$ in the Hanford epidemic previously mentioned, has shown the possibility of typhoid fever occurring after a very short incubation period or with slight or indefinite symptoms. The normal persons in our series (Table 3 ), therefore, have been chosen, with one exception, after elimination of suspicious infections or possible exposure to typhoid fever. The exception noted, A. G., was a physician who, during three years residence in a hospital, was constantly exposed to the disease, though having no memory of an infection. It is interesting to note that A. G. furnished the only positive reaction in our series of normal persons, and our suspicion that he had become sensitized to typhoid protein was further strengthened by a severe local and general reaction following a subsequent dose of typhoid vaccine.

The selection of a group of persons with a history of typhoid is a much more difficult task. The retention of a person in our series (Table 3) was conditioned on a history of one or more attacks of continued fever which had been called typhoid by the attending physician. Whenever in spite of a diagnosis of typhoid the patient's account of the disease contained an element of doubt, we have regarded the history as questionable. It will be seen that on a time basis these doubtful cases tend to group themselves at the beginning of the series before the use of the agglutination test became general.

Table 3 also shows the results of the test as applied to previously vaccinated persons and further classifies these results on a time basis. It will be seen that the percentage of negative reactions grows smaller as the time elapsing from vaccination to test grows shorter. The fact that 21 per cent. of persons vaccinated during the period from February to May, 1916, inclusive, failed to show positive reactions would indicate that the routine three doses of typhoid vaccine are not always enough to sensitize or immunize a person. On the other hand, ten out of thirteen persons showing negative skin reactions before vaccination (or revaccination) gave positive reactions after such vaccination. Of the three persons failing to give a positive reaction after retest, one had received three doses of vaccine within the two months preceding the test, one six doses in the year preceding, and one six doses in the two years preceding.

The insensitiveness of certain persons to typhoid protein is well illustrated by the following case:

R. L. S., a student, after six doses of typhoid vaccine failed to give a positive skin reaction. One month after her last test (eleven weeks after her 
last dose of vaccine) she developed typhoid fever, confirmed by blood culture and agglutination tests. She was treated with intravenous injections of GayClaypole vaccine and on recovery failed to give more than a very doubtful skin reaction.

This case further illustrates that sensitiveness bears a direct relation to protection.

Table 4 gives a summary of the local and general reactions to vaccination in persons previously receiving typhoidin tests. The reactions are arranged on the basis of response to the typhoidin test. In general it will be seen that the reactions of normal persons (both untested and negative to the skin test) differ very little from the reactions of previously vaccinated persons showing negative typhoidin tests. The revaccination of persons showing complete or partial sensitization, however, was attended by an increase in the severity of the reactions.

It is our growing conviction that typhoid immunity is a much less stable condition than has been generally supposed. ${ }^{27}$ Whether, as suggested by Wassermann and Sommerfeld, ${ }^{28}$ the reduced susceptibility produced by vaccination is liable to fluctuate under the influence of undernourishment, secondary infection and poor hygienic conditions; or the routine administration of three doses of typhoid vaccine is not a safe rule for every person, the fact is that many persons remain insensitive to typhoid protein after vaccination or lose their sensitiveness in increasing numbers as time elapses. In the words of $\mathrm{Gay}^{28}$ "in the case of human beings that have been vaccinated against typhoid fever we have no assurance that they are really protected and still less the assurance as to how long the protection lasts."

Pending further information on the duration of immunity, we have made a routine practice of advising the students of this university to return for a typhoidin test two years after vaccination. Students now being vaccinated (or revaccinated) are advised to return in three weeks for a typhoidin test. All persons showing a negative

27. Reference to our Table 3 will show that we secured negative typhoidin reactions in 50 per cent. of persons who had been vaccinated against typhoid three years previously; in 45 per cent. vaccinated two years previously; and in 27 per cent., one year previously. Lescohier (Duration of Immunity Following Smallpox Vaccination, Jour. Am. Med. Assn., 1913, 61, 487) has confirmed observations of Kitasato which show that 47 per cent. (48 per cent. Lescohier) of persons successfully vaccinated against smallpox may be successfully revaccinated after three years; 33 per cent. (33 per cent. Lescohier) of persons after two years, and 14 per cent. (28 per cent. Lescohier) after one year. The diminution of immunity following smallpox vaccination, as indicated by susceptibility to revaccination, shows a striking similarity in point of time to the diminution of cutaneous hypersensitiveness to typhoid protein.

28. Wassermann and Sommerfeld: Experimentelle Untersuchungen über die Wirksamkeit der Typhus und Cholera-schutzimpfung, Med. Klin., 1915.

28. Gay: New Uses of Specific Skin Tests in Certain of the Infectious Diseases, Am. Jour. Med. Sc., 1915, 149, 157. 
reaction are revaccinated, for even if the cutaneous sensitiveness to typhoid protein is of shorter duration than typhoid immunity, revaccination on the basis of a negative typhoidin reaction gives the student a safer margin of protection.

\section{SUMMARY AND CONCLUSIONS}

1. A stable preparation of typhoidin may be rapidly prepared by precipitating a concentrated broth culture of $B$. typhosus with 95 per cent. alcohol, and subsequent dehydration with absolute alcohol and absolute ether.

2. Definite reactions persisting forty-eight hours were produced in human beings by the intradermal injection of 0.05 c.c. of a 1 in 10,000 suspension of typhoidin in phenolated saline. In order to produce a similar reaction in rabbits, a dose of 0.1 c.c. of a 1 in 1,000 suspension of typhoidin was necessary.

3. It is imperative that no account be taken of the appearance of the reaction at the end of twenty-four hours. A positive typhoidin reaction is indicated by the presence, forty-eight hours after the test, of a well-defined erythematous papule at least $5 \mathrm{~mm}$. in diameter. Out of 108 positive reactions, the forty-eight hour papule measured $10 \mathrm{~mm}$. or over in twenty-six instances; the average measurement of 108 papules was $8.4 \mathrm{~mm}$.

4. Out of eighteen normal persons, seventeen gave negative reactions; out of twenty-six persons with a history of typhoid, nineteen gave positive reactions, one gave a doubtful, and six persons (four with questionable typhoid histories) gave negative reactions. Out of 152 persons previously vaccinated against typhoid, twelve of fifty-six vaccinated during 1916, three of eleven vaccinated during 1915, thirteen of twenty-nine vaccinated during 1914, and twenty-six of fiftytwo vaccinated during 1913 gave negative reactions (Table 3).

5. Ten of thirteen persons showing a negative reaction to the skin test before vaccination (or revaccination) gave positive reactions after vaccination (or revaccination).

6. The revaccination of previously vâccinated persons showing negative skin reactions produced local or general reactions no greater in intensity than the vaccination of normal persons, and much less severe than the reactions produced by the revaccination of persons showing positive skin reactions (Table 4).

7. The routine administration of three doses of typhoid vaccine is in many cases not sufficient to produce sensitization to typhoid protein, and presumptively, therefore, protection against typhoid fever. 
8. Even granting that typhoid immunity is of longer duration than cutaneous sensitiveness to typhoid protein, the disappearance of this sensitiveness furnishes an indication for revaccination of the person, and still allows a margin of safety within the as yet indefinite limits of typhoid immunity. There is as yet no evidence that a positive typhoidin test is not indicative of protection against typhoid fever. In two instances at least, in our experience, a negative typhoidin test after vaccination was followed by typhoid infection. We feel justified, then, in proceeding on the original assumption of Gay and Force that this test may be used as a measure of protection against typhoid. 